\title{
EXTRADURAL HAEMATOMA IN CHILDREN: SURGICAL EXPERIENCES AND PROSPECTIVE ANALYSIS OF 138 CASES
}

\author{
SMCN KHALED ${ }^{1}$, AHANIF $^{2}$, KMT ISLAM ${ }^{3}$, E MAHMOOD $^{4}$, SS HOSSAIN ${ }^{5}$
}

\begin{abstract}
:
Objective: The authors present their experiences in the management of extradural haematoma in children which involved an aggressive diagnostic approach, prompt surgical evacuation of the haematoma results in an excellent outcome.
\end{abstract}

Subjects and method: 138 consecutive patients with cranial extradural haematoma who underwent surgery in department of Neurosurgery from $1^{\text {st }}$ January 2006 to $31^{\text {st }}$ July 2009 were included in this prospective study. Each of the patients were evaluated in term of age, sex, mode of injury, localization of haematoma, clinical presentation, CT findings, operative measures and outcome.

Results: Out of 138 cases $72.47 \%$ were boys and $13.78 \%$ were girls. The boys and girls ratio was 2.64: 1. Age ranges from 1.8 to 15 years with a mean age of 9.49 years. Most of the victims are in first half of second decade of life and closely followed by the 5-10 years age group. The most common mode of injury was fall $\mathbf{4 0 . 5 8}$ $\%$, $(n=56)$ followed by Road traffic Accident (RTA) 31.89 $\%$, $(n=44)$.The Most common clinical presentation was altered sensorium $59.43 \%$, $(n=82)$, followed by Headache I Vomiting $56.53 \%$, $(\mathrm{n}=78)$

Conclusion: Extradural haematoma in children is a recognized and one of the most rewarding neurosurgical emergencies. It must be recognized and evacuate early to prevent potential mortality and morbidity. Many factors affect the outcome of extradural haematoma surgery. In addition to influence of presence cranial fractures,

1. Dr. Sharif Md Noman Khaled Chowdhury, Assistant Professor, Department of Neurosurgery, Dhaka Medical College, Dhaka.

2. Dr. Abdul Hanif, Assistant Professor, Department of Pediatric Surgery, Dhaka Medical College, Dhaka.

3. Dr. K M Tarikul Islam, Resident, Department of Neurosurgery, Dhaka Medical College, Dhaka.

4. Dr. Ehsan Mahmood, Professor,Department of Neurosurgery, Dhaka Medical College, Dhaka.

5. Dr. Sk. Sader Hossain, Professor\& Head of the department, Department of Neurosurgery, Dhaka Medical College, Dhaka. Correspondence to: Dr. Chowdhury Noman Khaled S M, M S., Assistant Professor, Department of Neurosurgery, Dhaka Medical College Hospital, Dhaka, Bangladesh. Phone +8801819019415, e-mail-nomankhaled@yahoo.com associated brain lesions and pre-operative neurological condition of patient, duration of time interval between onset of coma and surgical intervention, morbidity and mortality have also been shown to be affected by age with better prognosis in patients under 10 years of age.

\section{Introduction:}

EDH is a unique form of neurotrauma, being potentially lethal, yet easily remedied if diagnosed early and promptly treated. For this reason, the outcome of treatment of EDH has remained a yardstick to measure the efficacy of neurotrauma service ${ }^{1}$.The incidence of EDH among traumatic brain injury (TBI) patients has been reported to be in the range of 2.7 to $4 \% 2$. It has been estimated that EDH represents 2$3 \%$ of all head injuries in the pediatric population. ${ }^{3}$ The mean age of pediatric patients harboring EDH is between 6 and 10 years and EDH is even rarer among infants under the age of 12 months ${ }^{2-5}$.

It is recognized that EDH in children differ from EDH in adults in that the haematoma may follow a trivial injury, the symptoms are different, the course is more insidious, associated skull fracture is infrequent ${ }^{6}$ and this make it difficult to diagnose and often challenging to manage. Furthermore, the criteria for utilizing surgical evacuation vs conservative management have remained ill-defined. Thus, the lack of any guidelines regarding the appropriate management of EDH in pediatric patients and particularly in infants makes the management of this specific group of patients all the more complicated ${ }^{3}$.The reported mortality rates of $\mathrm{EDH}$ in children are quite different varying between $0 \%$ and $50 \%{ }^{7}$ These considerable variations in the outcome and lack of data that provide a clear cut picture of EDH in children prompted us to carry out this study. We present our experience with 138 cases of acute epidural hematoma in children less than 18 years of age. Here, we discuss the age-related findings and the differences with adults. 


\section{Clinical Materials and Methods:}

Between January 2006 and July 2009, 138 patients were surgically managed at the Department of Neurosurgery, Dhaka Medical College Hospital. This prospective study includes these consecutive patients. The patients were categorized according to age and were divided into four groups, for analysis and comparison of their presentation and management. Group A: aged 0 to 2 years - 6 cases (4.35\%), Group B: aged 3 to5 years -21 cases (15.22\%); Group C aged 6 to 10 years- 50 cases (36.23), Group D aged 11 to 18 years- 61 cases (44.20\%). A meticulous physical examination, with an emphasis on neurological function, was performed on admission. The diagnosis of haematoma was confirmed by CT scanning. In addition, standard epidemiological data including age, sex and mode of injury, presence of skull fracture, presenting clinical features from injury to surgery, preoperative Glasgow Coma Score (GCS) and pupillary reaction to light, presence of other injury, CT findings, localization of haematoma, the effect of injury and timing from injury to surgery were recorded. Surgical decision was determined by the following clinical and radiologic parameters: 1) Unconscious or deterioration of neurological status in patients with a Extradural hematoma larger than $20 \mathrm{ml}, 2$ ) Volume of the hematoma $30 \mathrm{~mL}$ even if the patient is awake and free from neurological deficit, 3) Volume of the hematoma ?20 $\mathrm{mL}$ when located in critical sites, such as posterior cranial fossa or temporal base, 4) midline Shift $>0.5 \mathrm{~cm}$ with deterioration of level of consciousness,5) Increase in the hematoma size.

We calculated the volume of the hematoma by measuring the diameters (length, width, and height) and considering hematoma shape as an ellipsoid. In particular, we used the following method: $a \times b \times c$ 0.52 , where "a," "b," and "c" represent the diameters of the hematomas. ${ }^{8}$

Patients with spontaneous EDH or patients with EDH of unknown etiology and patients treated conservatively were excluded from current study. Asymptomatic patients, patients presenting only minor symptoms with small haematoma (thickness less than $20 \mathrm{~mm}$ ), patients admitted 24 or more hour after trauma with neurological stable condition were selected for conservative management. These patients were very closely observed clinically by monitoring level of consciousness, focal neurological signs, and vital signs and follow up CT scan was done to asses clot size. We had to operate on 7 such cases when patient's level of consciousness and GCS score were deteriorated and repeat CT scan showed increase in size of haematoma. All the cases were operated on emergency basis. Surgical management consisted of craniotomy under general endotracheal anesthesia and removal of the underlying hematoma .Outcome was assessed on an outpatient basis. The Glasgow Outcome Scale (GOS) was utilized for evaluating the outcomes.

\section{Results:}

\section{Clinical Parameters:}

Ages of the patients were ranged from 1.8 years (One year eight months) to 18 years with a mean age of 9.49 years. Age distribution demonstrates that most of the victims were in first half of second decade of life. There were $72.47 \%$ male and $27.54 \%$ female patients; the ratio between them was $2 \cdot 64: 1$. The most common mode of injury was fall $(40.58 \%)$ followed by Road traffic Accidents (RTA) 31.89 .Most of our road traffic accidents involved passengers of "Three Wheel Vehicles" like Baby taxi and Rickshaw. In our series, commonest clinical presentation was altered sensorium $59.43 \%$, followed by Headache / Vomiting $56.53 \%$,. $18.85 \%$ patients had neurological deficit (hemiparesis). Early seizures were recorded in $10.15 \%$ children presenting with EDH. The classically described "lucid interval" $i$, e. a patient who was initially unconscious, then wake up and secondarily deteriorates, was observed in $27.54 \%$ cases (TableII) .According to CT findings, temporo-parietal region was involved in $42.03 \%$ followed by frontal region in $30.44 \%$. The posterior fossa involvement was very few, $1.45 \%$ cases . Table-III). $62.32 \%$ patients showed skull fractures demonstrated either by $\mathrm{x}$-ray, or CT scan or discovered at the time of operation. Associated injuries were present in $27.53 \%$ cases (Table-IV). All the cases were operated on emergency basis and two third of cases $(66.76 \%)$ were operated on within the first 24 hours (Table $V$ ).

Twelve patients ( $8.69 \%)$ were expired. Among these unfortunate 12 patients, 5 had associated brain injuries, 8 cases were deeply unconscious and 9 of these had fixed pupil / pupils at the time of admission. 
Table-I

Mode of Injury

\begin{tabular}{lcc}
\hline Cause of injury & No. of population & Percentage \\
\hline Fall from height & 56 & 40.58 \\
RTA & 44 & 31.89 \\
Assaults & 31 & 22.47 \\
Fall of heavy weight on head & 7 & 5.07 \\
\hline
\end{tabular}

Table-II

Clinical Presentations

\begin{tabular}{lcc}
\hline Signs / Symptoms & No. of population & Percentages \\
\hline Altered sensorium & 82 & 59.43 \\
Headache / Vomiting & 78 & 56.53 \\
Lucid interval & 38 & 27.54 \\
Neurodeficit (hemiparesis) & 26 & 18.85 \\
Seizure & 14 & 10.15 \\
\hline
\end{tabular}

Table-III

Population distributions as per site of Haematoma

\begin{tabular}{lcc}
\hline Site of Haematoma & No. of population & Percentages \\
\hline Temporoparietal & 58 & 42.03 \\
Frontal & 42 & 30.44 \\
Parietal & 19 & 13.77 \\
Temporal & 15 & 10.87 \\
Occipital & 2 & 1.45 \\
Posterior fossa & 2 & 1.45 \\
\hline
\end{tabular}

Table-IV

Associated injuries

\begin{tabular}{lcc}
\hline Associated injuries & No. of population & Percentages \\
\hline Fracture & 86 & 62.32 \\
Contusion / ICH Acute & 34 & 24.64 \\
Subdural Haematoma & 4 & 2.89 \\
\hline
\end{tabular}

Table-V

Time interval between trauma and operation

\begin{tabular}{lcc}
\hline Hours & No. of population & Percentages \\
\hline $0-12$ & 14 & 10.15 \\
$13-24$ & 78 & 56.63 \\
$25-48$ & 46 & 33.34 \\
\hline
\end{tabular}

Discussion:

Traumatic extradural haematoma (EDH) in children have some unique features when compared with those in the adult population. Our institution is not a pediatric neurotrauma center but a neurosurgery department that admits patients of all ages with an average number of 15,000 neurotrauma admissions per year. Therefore, there is every reason to assume that the data we present are a true reflection of the comparison with those of the adult population. Traumatic extradural haematoma (EDH) in children accounted for $15.86 \%$ of the 870 patients with an epidural hematoma operated in our institution in the same period. This lower incidence of acute epidural hematoma in the children compared with adults is also reported in other series and is attributable to the tight adherence of the dura mater to the inner table of the skull. ${ }^{8}$

Our analysis has identified that EDH is more frequent in 11 years of age or above among children $(44.21 \%)$ ). Only $4.35 \%$ victims were infants. This data is correlated with other reported series of EDH in children $7,9,10-13$ This is due to the high-velocity trauma mechanism in the older age group ${ }^{8}$. In these series majority of patients were boys $(74.47 \%)$.It is similar to other reported series of EDH in children $10,11,12,14$. and this trends was observed even in infants (66.67\%). It was reflecting the natural tendency of boys to indulge in risky play activities.

In our series, falls were the predominant modes of injury $(40.58 \%)$ followed by RTA $(31.89 \%$,). Out of 56 victims of fall, (29/56) were in domestic (22/56), in sports and recreation; and (7/56) were in work. Similar results have been reported by other authors $7,8,10,14$ but Dhellemmes found that $64 \%$ patients with EDH had been involved RTA and other causes had occurred less frequently ${ }^{11}$. RTA is the commonest mode of injury in adult also. ${ }^{13}$ The cause of accident in this subcontinent include a poor design and maintenance of roads, poorly maintained vehicle with no safety facilities, apathy by authorities, poorly trained drivers and most importantly public and children awareness of prevention of accidents etc. These factors play important role in road traffic accidents and head injuries including EDH ${ }^{15}$

Historically, bleeding from middle meningeal artery has been considered as the main source for EDH. But in a recent report on EDH in 102 pediatrics patients and 387 adults, arterial bleeding identified as the source of EDH in $36 \%$ of adults and in $18 \%$ of children. 
2,16 In $31 \%$ of pediatrics patients a bleeding source could not be identified and venous bleeding accounted for approximately $32 \%$ of EDH in this age group 2 .

In these series most patients $(59.43 \%$,) had altered sensorium and we strongly believe that this is the most significant sign of EDH in Children. It is supported in other reported series also ${ }^{9-11} .56 .53 \%$ Children had headache associated with persistent vomiting. It is nonspecific but important clinical sign. In our series we evaluated other clinical signs such as hemiparesis $(18.84 \%)$ and pupil dilatation (22\%). The classically described "lucid interval" was observed in $27.54 \%$ cases in our series. It is almost similar to Ersahin et al ${ }^{17}$ who had found lucid interval in $37 \%$ cases but was contradictory to Hanci et al ${ }^{10}$ who discovered it was only in 11.125 cases. In our series, early seizure was noted in $10.15 \%$ cases. Our data is in agreement with Lahat et al,${ }^{4}$ who reported early seizure in $8 \%$ of pediatrics patients.

Simpson et al ${ }^{18}$ pointed out that diagnosis of EDH in a child may not be made until early clinical feature of raised ICP is present. In our series, we evaluated clinical signs as expected. Accordingly early detection of the lesion is critical. The sign / symptoms were nonspecific in majority of cases. Based on clinical findings early diagnosed was established only in small percentage of cases. We believe that CT scan of head should be done routinely in suspected case as early diagnosis of EDH is mandatory for good recovery as radiological changes always occur earlier than clinical changes and should be monitor to predict the clinical progression ${ }^{18-20}$.

In this series, the temproparietal region (42.03\%) was the commonest site followed by frontal region. It is similar to Hanci et al ${ }^{10}$ who had opinion that EDH originating in the fronto temporal region does not spread to the frontal region. A possible explanation is the adherence of dura at the suture line ${ }^{21}$. As regard location, frontal haematomas have shown a better prognosis and a slower course than convexity haematomas. It is contrary to Mohanty et al ${ }^{16}$ who found that the site of haematoma had no correlation with the final outcome; whereas the GCS score and the associated parenchymal injuries had a strong correlation with the outcome both in adult and children. It is in agreement with our experiences.

In our series, cranial fractures were present in 62.32 $\%$ patients' with significantly lower mortality rate. In many reported series, cranial fractures were in between $70-95 \%$ 2, 14, 22-26. The impact of fracture on outcome is controversial. Kuday et al. ${ }^{25}$ observed a significant relationship between cranial fractures and adverse outcome in 115 patients undergoing surgery for EDH. Lee et al. ${ }^{27}$ did not see this relationship in a series of 200 patients managed similarly .But Rivas et al. ${ }^{28}$ reported a significantly lower mortality rate in patients with cranial fractures which is in strong agreement with our findings.

In our series, associated brain injuries discovered in $27.53 \%$ cases. These are predominantly contusions, intra-cerebral haemorrhage; sub dural haematomas and diffuse brain swellings. The incidence of associated lesion in reported series is less in pediatrics age group 2,14,16,22, SDH and / or parenchymal injuries in association with EDH lower the chance of good outcome ${ }^{2}$.

Despite a steady decline in mortality, in this series, twelve patients (8.69 \%) were expired. Among these unfortunate patients, $41.67 \%$ had associated brain injuries, $66.67 \%$ cases were deeply unconscious and $75 \%$ victims of these had fixed pupil / pupils at the time of admission. Mazza et al. ${ }^{9}$ discovered associated brain lesions in $40 \%$ of his cases, over all mortality rate was $17 \%$, with $14 \%$ operative mortality. Ersahin et al. ${ }^{17}$ found $10 \%$ overall mortality, with mortality rate in the CT and plain x-ray groups were $6 \%$ and $16 \%$ respectively. Though the mortality rate in children was less than adult's series ${ }^{13}$ but $0 \%$ mortality as proposed by Ammiriti ${ }^{29}$ and Bricolo ${ }^{30}$ should be the goal of EDH surgery.

\section{Conclusion:}

Extradural haematoma in children is one of the most rewarding neurosurgical emergencies. It must be recognized and evacuate early to prevent potential mortality and morbidity. Our experiences of 138 surgically managed cases involved an aggressive diagnostic approach, prompt surgical evacuation of the haematoma results in an excellent outcome. Many factors affect the outcome of extradural haematoma surgery. In addition to influence of presence cranial fractures, associated brain lesions and pre-operative neurological condition of patient, duration of time interval between onset of coma and surgical intervention, morbidity and mortality have also been shown to be affected by age - with better prognosis in patients under 10 years of age. 


\section{References:}

1. Jones NR, Molloy CJ; Kloeden CN; North JB; Simpson DA. Extradural haematoma: trends in outcome over 35 years. British Journal of Neurosurgery 1993; 7: 465-471.

2. Bullock MR, Chesnut R, Ghajar J, Gordon D, Hartl R, Newell DW et al.: Surgical Management of acute epidural haematomas. Neurosurgery 2006; vol. 58:(Supplement) 52-7.

3. Ciurea AV; Kapsalaki EZ; Coman TC; Roberts JL; Robinson III JS; Tascu A; Brehar F; Fountas $\mathrm{KN}$. Supratentorial epidural hematoma of traumatic etiology in infants. Childs Nerv Syst 2007; 23: 335-341.

4. Lahat E, Sheinman G,Feldman Z,Brazilai A,Harel $\mathrm{R}$, Brazilay $Z$ et ai.Metabolic and clinical markers of prognosis in the era of $\mathrm{CT}$ imaging in children with epidural haematoma. Pediatr Neurosurg 2000; 33:70 75.

5. Schutzman S, Barnes P,Mantello M, Scoot R: epidural haematoma in children. Ann Emerg Med 1993, 22:535-541.

6. Jamjoom A, Cummins B, Jamjoom ZA. Clinical characteristics of traumatic Extradural haematoma: a comparison between children and adults. Neurosurg, rev 1994;277-281.

7. Pasaoglu A, Orhan C, Koc K, selcuklu A, Akdemir $A$ and Uzunoglu $\mathrm{H}$. Traumatic Extra dural haematoma in paediatric age group. Acta Neurochir (wien) 1990; 106:136-139.

8. Rocchi G, MD; Caroli EM,D; Raco A, MD; Salvati M,MD; Delfini R, MD. Traumatic Epidural Hematoma in Children. J Child Neurol 2005;20:569-572

9. Mazza C, Pasqualin A, Ferioti G, and Da Pian : Traumatic Extradural Haematoma In children: Experience with 62 cases. Acta Neurochir 1982, 65:67-80

10. Hanci M, Uzan M, Kuday C,Sarioglu A C, Akar Z, Canbaz B at el. : Epidural Haematomas In Infancy And Childhood: Report of 54 Cases. Turkis Neurosurgery 1994; 4:73-76.

11. Dhellemmes $P$, LejeuneJP,Christianes JL, Combelles G: traumatic extradural haematoma in infancy and childhood. Experience with 144 cases.J Neurosurg 1985, 62:861-864
12. Milza PG, Nardi PV, Gigla G, La Motta a: Extradural haematoma in infancy and childhood.Report on 176 cases. J Pediatric Neuroscience 1985; 5:117-122

13. Chowdhury Noman Khaled SM, Raihan MZ, Chowdhury FH , Ashadullah ATM ,Sarkar MH , Hossain SS. Surgical management of traumatic extradural haematoma: Experiences with 610 patients and prospective analysis. Indian Journal of Neurotrauma (IJNT),2008, Vol. 5, No. 2, pp. 75-79

14 . Leggate JRS, Lopes Ramos N, Genetori I, Lena G,Choux M. Extradural haematoma I infancy,B J Neurosurg 1889,3:533-540.

15. Kumar R M Ch, Shrivastava AK M Ch, Singhal U M S, Saraswat B M S*, Mahapatra AK M Ch. Compound head injury in 46 pediatric patients. Indian Journal of Neurotrauma (IJNT) 2009, Vol. 6, No. 1 , pp. $43-48$

16. Mohanty A, Kolluri VR, Subbakrishna DK, Satish S, Mouli BA, Das BS: Prognosis of extradural haematomas in children, Pediatr Neurosurg 1995; 23:57-63

17. Ersahin $\mathrm{Y}$, Mutluer S, Guzelbag E: Extradural Haematoma analysis of 146 cases. Child's Nerv Syst 1993; 9:96-99.

18. Simpson DA, Cockington RA, Hanieh A, Raftos $J$, Reilly PL: Head injuries in infant and young children: the value of paediatric coma scale. Review of literature and report on study.Child Nerv Syst 1991, 7:183-190.

19. Bor-Sen-Shu E, Aguiar PH, Almedida Leme RJ, Mandel M, Andrade AF, Marino RJ. Epidural hematomas in the posterior cranial fossa. Neurosurg 2004, 16(2)

20. Bozbuga M, Izgi N, Polat G et al: Posterior fossa epidural hematomas: Observation on a series of 73 cases. Neurosurg Rev 22:34-40;1999

21. Choux M,Grisoli F. Baurand C, Peragut JC : Extra dural haematoma in children.Child's Brain1975; 1:337 -347

22. Pillay R,Peter J: Extradural haematoma in children.S Afr Med J 1995, 85:672-674

23. Hunt J,Hill D, Besser M, West R, Roncal $S$ :Outcome of patient with neurotrauma: the effect of a recognized trauma system .Aust N Z J Surg $1996,65: 83-86$ 
24. Jamjoom A: The difference in the outcome of surgery for traumatic Extradural Haematoma between patients who are admitted directly to the neurosurgical unit and those referred from another hospital. Neurosurg Rev 1997; 20:227230

25. Kuday C, Uzan M, Hanci M: Statistical analysis of the factors affecting the outcome of Extradural Haematomas: 115 cases. Acta Neurochir (Wien) 1994;131: 203-206

26. Sullivan T, Jarvik J, Cohen W: Follow-up of conservatively managed epidural haematomas: Implications for timing of repeat CT. AJNR AM J Neuroradiol1999; 20:107-113
27. Lee EJ, Hung YC, Wang LC, Chung KC, Chen $\mathrm{HH}$ : Factors influencing the functional outcome of patients with acute epidural haematomas: Analysis of 200 patients undergoing surgery. $\mathrm{J}$ Trauma 1998; 45:946-952,

28. Rivas JJ, Lobato RD, Sarabia R, Cordobes F, Cabrera A, Gomez P: Extradural haematoma: An analysis of factors influencing the ocourses of 161 patients. J Neurosurgery 1988; 23:44-51.

29. Ammirati M, Tomita T. Epidural hematomas in infancy and childhood. J Pediatric Neuroscience 1985; 1:123-128

30. Bricolo AP. Pasut LM: Extradural haematoma: Toward zero mortality. A prospective study. Neurosurgery 1984, 14:8-12. 